\title{
Inhibition of nitric oxide synthesis improves left ventricular contractility in neonatal pigs late after cardiopulmonary bypass
}

R R Chaturvedi, V E Hjortdal, E V Stenbog, H B Ravn, P White, T D Christensen, A B Thomsen, J Pedersen, K E Sorensen, A N Redington

\begin{abstract}
Background-Following neonatal open heart surgery a nadir occurs in left ventricular function six to 12 hours after cardiopulmonary bypass. Although initiated by intraoperative events, little is known about the mechanisms involved.

Objective-To evaluate the involvement of nitric oxide in this late phase dysfunction in piglets.
\end{abstract}

Design-Piglets aged 2 to 3 weeks (4-5 kg) underwent cardiopulmonary bypass $(1 \mathrm{~h})$ and cardioplegic arrest $(0.5 \mathrm{~h})$ and then remained ventilated with inotropic support. Twelve hours after bypass, while receiving dobutamine $(5 \mu \mathrm{g} / \mathrm{kg} / \mathrm{min})$, the left ventricular response to non-selective nitric oxide synthase inhibition $\left(1-\mathrm{N}^{\mathrm{G}}-\right.$ monomethylarginine (1-NMMA)) was evaluated using load dependent and load independent indices $\left(E_{e s}\right.$, the slope of the end systolic pressure-volume relation; $M_{w}$, the slope of the stroke work-end diastolic volume relation; $\left[\mathrm{dP} / \mathrm{dt}_{\text {max }}\right]_{\mathrm{edv}}$, the slope of the $\mathrm{dP} / \mathrm{dt}_{\max }$-end diastolic volume relation), derived from left ventricular pressure-volume loops generated by conductance and microtip pressure catheters. Results-10 pigs received $7.5 \mathrm{mg}$ 1-NMMA intravenously and six of these received two additional doses $(37.5 \mathrm{mg}$ and $75 \mathrm{mg}) . \mathrm{E}_{\mathrm{es}}$ (mean (SD)) increased with all three doses, from 54.9 (40.1) $\mathrm{mm} \mathrm{Hg} / \mathrm{ml}$ (control) to $86.3(69.5)$ at $7.5 \mathrm{mg}, 117.9(65.1)$ at $37.5 \mathrm{mg}$, and $119(80.4)$ at $75 \mathrm{mg}(\mathrm{p}<0.05)$. At the two highest doses, $\left[\mathrm{dP} / \mathrm{dt}_{\text {max }}\right]_{\text {edv }}$ increased from 260.8 (209.3) (control) to $470.5(22.8)$ at $37.5 \mathrm{mg}$ and $474.1(296.6)$ at $75 \mathrm{mg}(\mathrm{p}<0.05)$; and end diastolic pressure decreased from $16.5 \quad$ (5.6) $\mathrm{mm} \mathrm{Hg}$ (control) to $11.3(5.0)$ at $37.5 \mathrm{mg}$ and $11.4(4.9)$ at $75 \mathrm{mg}(\mathrm{p}<0.05)$.

Conclusions-In neonatal pigs 12 hours after cardiopulmonary bypass with ischaemic arrest, low dose 1-NMMA improved left ventricular function, implying that there is a net deleterious cardiac action of nitric oxide at this time.

(Heart 1999;82:740-744)

Keywords: ventricular function; nitric oxide; neonatal pigs; cardiovascular surgery; paediatric cardiology

After neonatal open heart surgery, ventricular function is initially depressed but adequate, then deteriorates further with a nadir in cardiac performance occurring six to 12 hours postoperatively, followed by a gradual improvement. ${ }^{1} 2$ This sequence is initiated by intraoperative events and is a manifestation of tissue injury and intracardiac and systemic inflammation. There has been extensive investigation of reperfusion and early postoperative ventricular function in terms of the involvement of autacoids, free radicals, cytokines, and neutrophils, and the impact of different cardioplegic strategies. ${ }^{34}$ However, there is a lack of information on the mechanisms of this late phase ventricular dysfunction, which is usually more severe and of greater clinical significance than that occurring immediately after the operation.

Nitric oxide (NO) is one possible mediator of late phase ventricular dysfunction, because high concentrations decrease myocyte twitch and NO contributes to impaired cardiac function in conditions characterised by intracardiac or systemic inflammation with increased NO production $^{5}$ - for example, cardiac allograft rejection, myocarditis, and septicaemia. ${ }^{6-8}$ However, evaluation of the cardiac effects of nitric oxide donors and nitric oxide synthase inhibitors is made difficult by their prominent vascular actions which alter loading conditions and require the use of load independent indices of left ventricular function. ${ }^{9}$

The role of NO in this late phase ventricular dysfunction was examined in neonatal pigs 12 hours after cardiopulmonary bypass with ischaemic arrest. We assessed the cardiac effects of nitric oxide synthase inhibition by low dose $1-\mathrm{N}^{\mathrm{G}}$-monomethylarginine (1-NMMA) in these animals from load independent indices of left ventricular function. These were derived from real time pressure-volume loops generated under varying preload using conductance and microtip pressure catheters. To our knowledge, this is the first examination of the pathophysiology of late phase ventricular dysfunction after cardiopulmonary bypass and ischaemic arrest.

\section{Methods}

PREPARATION OF ANIMALS

This investigation conformed to the Guide for the care and use of laboratory animals published by the US National Institutes of Health (NIH Publication No 85-23, revised 1996). The institutional animal research committee approved the use of Danish Landrace pigs, 2 to 3 weeks of age $(4-5 \mathrm{~kg})$. Animals were sedated with midazolam $(0.3 \mathrm{mg} / \mathrm{kg})$ and fentanyl $(50$ 
$\mu \mathrm{g} / \mathrm{kg} / \mathrm{h})$, and paralysed with pancuronium (0.1 $\mathrm{mg} / \mathrm{kg}$ ), all given intravenously. They were then intubated and ventilated. Subsequently sedation was maintained with fentanyl $(20 \mu \mathrm{g} / \mathrm{kg} / \mathrm{h})$ and intermittent boluses of midazolam (0.1 $\mathrm{mg} / \mathrm{kg}$ ), and paralysis with intermittent boluses of pancuronium $(0.1 \mathrm{mg} / \mathrm{kg})$. Each animal received two doses of ampicillin $(25 \mathrm{mg} / \mathrm{kg}$ intravenously, six hours apart). The right and left carotid arteries, right internal jugular vein, and a peripheral ear vein were cannulated, and suprapubic bladder catheterisation was performed.

SURGERY AND CARDIOPULMONARY BYPASS

After median sternotomy and heparinisation (300 IU of unfractionated heparin $/ \mathrm{kg}$ ), animals were put on cardiopulmonary bypass using a standard clinical neonatal circuit with right atrial and ascending aorta cannulation, a membrane oxygenator (Dideco, Milan, Italy), and a roller pump (200 ml/kg flow). Animals underwent 60 minutes of cardiopulmonary bypass $\left(20^{\circ} \mathrm{C}\right.$, packed cell volume $\left.20 \%\right)$ and 30 minutes of aortic cross clamping and cardioplegic arrest with cold crystalloid cardioplegia (St Thomas' solution 1 (Plegisol), $30 \mathrm{ml} / \mathrm{kg}$, $4^{\circ} \mathrm{C}$ into the aortic root at $40 \mathrm{~mm} \mathrm{Hg}$ ). Protamine sulphate ( $1 \mathrm{ml} / 1000$ IU heparin) was given immediately after bypass.

POST-CARDIOPULMONARY BYPASS CARE

Routine intensive care vital signs (blood pressure, heart rate, central venous pressure, rectal and peripheral temperature, urine output), ventilator tidal volumes and pressures were monitored. Temperature was maintained at $38^{\circ} \mathrm{C}$ with a heating pad and radiant lights. Arterial gases were checked every hour and appropriate adjustments made in ventilator settings. Packed cell volume was maintained at 30-35\% with donor blood. Ionised calcium was kept at $1.0 \mathrm{mmol} / 1$ with slow boluses of 0.1 $\mathrm{mmol} / \mathrm{kg}$ calcium gluconate intravenously. Polygeline (Haemaccel) was used as additional colloid to maintain the right atrial pressure at 5-10 $\mathrm{cm} \mathrm{H}_{2} \mathrm{O}$, and the animals also received frusemide (furosemide), $0.5 \mathrm{mg} / \mathrm{kg} / \mathrm{h}$ intravenously. All animals received dobutamine after cardiopulmonary bypass, and dose adjustments were permitted $(2.5-10 \mu \mathrm{g} / \mathrm{kg} / \mathrm{min}$ range) except during the period of left ventricular function measurements, when the dose was kept at $5 \mu \mathrm{g} / \mathrm{kg} / \mathrm{min}$. No adjustments in ventilation, inotropes (dobutamine, calcium), sedative and paralytic drugs, or preload were made within 45 minutes of the measurements. The aim was to avoid acidosis and to maintain a systolic arterial blood pressure of more than $80-90 \mathrm{~mm} \mathrm{Hg}$, a urine output of more than $1 \mathrm{ml} / \mathrm{kg} / \mathrm{h}$, and adequate peripheral perfusion.

ASSESSMENT OF LEFT VENTRICULAR FUNCTION The conductance catheter has been extensively validated for left ventricular volume measurement and details of the theory ${ }^{10}$ and of our customised conductance catheter system are presented elsewhere. ${ }^{112}$ Left ventricular function was assessed with the chest and pericar- dium widely open and with ventilation stopped at end expiration, at 12 hours after cardiopulmonary bypass (control) and then again at 15 minutes after each dose of 1-NMMA (Calbiochem). L-NMMA was infused intravenously over five minutes in $5 \mathrm{ml}$ of normal saline, at doses of $15 \mathrm{mg}(1.5 \mathrm{mg} / \mathrm{kg}), 37.5 \mathrm{mg}(7.5$ $\mathrm{mg} / \mathrm{kg})$, and $75 \mathrm{mg}(15 \mathrm{mg} / \mathrm{kg})$. Left ventricular function measurements took five minutes, and so the total drug dosing and response measurement schedule took about 75 minutes $(3 \times 25$ minutes).

Real time left ventricular pressure-volume loops were generated using a conductance catheter (4F, NuMed, Hopkinton, New York, USA) inserted retrogradely from the right carotid artery into the left ventricular apex under fluoroscopic control, and a microtip pressure catheter (2 F, Millar, Houston, Texas, USA) inserted through the left ventricular apex and secured with a pledget and purse string suture. The conductance catheters were custom built single field $4 \mathrm{~F}$ catheters (interelectrode distance $0.43 \mathrm{~cm}$ ) with eight platinum ring electrodes. The conductance catheter was manipulated until all five segmental volumes were in phase and a counterclockwise rotating pressure-volume loop was formed. All volume measurements were corrected for blood resistivity and parallel conductance. Parallel conductance was determined by the hypertonic saline method using an injection of $0.2 \mathrm{ml}$ of $20 \% \mathrm{NaCl}$ into the pulmonary artery. ${ }^{10}$ The dimensionless gain constant $\alpha$ was assumed to be unity. Once a stable position was obtained for the conductance catheter in the left ventricular apex, no further manipulation was required in any of the pigs during baseline and drug doses, supporting our use of a constant $\alpha$. Preload was varied by transient (10 seconds) snaring of the inferior caval vein. The conductance catheter signal encoding volume and ECG data was fed to a stimulator/processor unit (Sigma-5-DF, Cardiodynamics, Leiden, Netherlands) and then to a committed microcomputer, where it was integrated with the amplified pressure signals (Fylde isotransducer amplifier, London, UK) in custom designed software. From the stored data, load independent indices were derived from left ventricular pressure-volume loops generated with variable preload (inferior caval vein snaring) and load dependent indices from steady state left ventricular pressure-volume loops. The load independent indices examined were: $\mathrm{E}_{\mathrm{es}}$, the slope of the end systolic pressure-volume relation; $\mathrm{E}_{\mathrm{ed}}$, the slope of the end diastolic pressure-volume relation; $\left[\mathrm{dP} / \mathrm{dt}_{\max }\right]_{\mathrm{edv}}$, the slope of the $\mathrm{dP} / \mathrm{dt}_{\max }$-end diastolic volume relation; and $\mathrm{M}_{\mathrm{w}}$, the slope of the stroke work-end diastolic volume relation. The end diastolic pressure-volume relation was fitted with a straight line. Load dependent indices used were: $\mathrm{dP} / \mathrm{dt}_{\max }$, the maximum value of the time derivative of left ventricular pressure; $\mathrm{dP} / \mathrm{dt}_{\min }$, the minimum value of the time derivative of left ventricular pressure; $P_{\max }$, maximum value of left ventricular pressure; $P_{\text {ed }}$, the left ventricular end diastolic pressure; and $\tau$, the time constant of isovolumic relaxation. 
Table 1 Response to l- $N^{G}$-monomethylarginine (NMMA), $7.5 \mathrm{mg}, 37.5 \mathrm{mg}$, and $75 \mathrm{mg}$

\begin{tabular}{llllll}
\hline & Pre-NMMA & NMMA 7.5 mg & NMMA 37.5 mg & NMMA 75 mg & N Value \\
\hline $\mathrm{E}_{\mathrm{es}}(\mathrm{mm} \mathrm{Hg} / \mathrm{ml})$ & $54.9(40.1)$ & $86.3(69.5)^{\star}$ & $117.9(65.1)^{\star}$ & $119(80.4)^{\star}$ & 0.009 \\
$\mathrm{M}_{\mathrm{w}}(\mathrm{mm} \mathrm{Hg} / \mathrm{ml})$ & $77.4(36.0)$ & $88.8(33.3)$ & $99.2(32.0)$ & $95.5(35.6)$ & 0.1 \\
{$\left[\mathrm{dP}_{\mathrm{dt}} \mathrm{dt}_{\max }(\mathrm{mm} \mathrm{Hg} / \mathrm{s} / \mathrm{ml})\right.$} & $312.6(209.3)$ & $359.7(227.7)$ & $470.5(222.8)^{\star}$ & $474.1(296.6)^{\star}$ & 0.02 \\
$\mathrm{E}_{\mathrm{ed}}(\mathrm{mm} \mathrm{Hg} / \mathrm{ml})_{\mathrm{dP} / \mathrm{dt}_{\max }(\mathrm{mm} \mathrm{Hg} / \mathrm{s})}$ & $5.4(2.9)$ & $3.5(1.2)$ & $4.0(2.6)$ & $4.2(2.5)$ & 0.13 \\
$\mathrm{dP}_{\mathrm{dt}}(\mathrm{mm} \mathrm{Hg} / \mathrm{s})$ & $1907(715)$ & $1979(765.7)$ & $2043(857.9)$ & $2149(999.6)$ & 0.65 \\
$\tau(\mathrm{s})$ & $1802(689.1)$ & $1870(774.4)$ & $1849(983.1)$ & $1938(1056)$ & 0.93 \\
$\mathrm{P}_{\max }(\mathrm{mm} \mathrm{Hg})$ & $27.5(11.2)$ & $27.8(10.2)$ & $23.3(6.8)$ & $23.9(6.3)$ & 0.97 \\
$\mathrm{P}_{\text {ed }}(\mathrm{mm} \mathrm{Hg})$ & $102(30.1)$ & $106.9(32.9)$ & $99.6(41.9)$ & $105.6(46.6)$ & 0.67 \\
\hline
\end{tabular}

Data are mean $(\mathrm{SD})$.

*Significant at $\mathrm{p}<0.05$ for multiple comparisons with pre-NMMA value using Dunnett's test.

$\mathrm{dP} / \mathrm{dt}_{\max }$, maximum value of the time derivative of left ventricular pressure; $\mathrm{dP} / \mathrm{dt}_{\min }$, minimum value of the time derivative of left ventricular pressure; $\left[\mathrm{dP} / \mathrm{dt}_{\max }\right]_{\mathrm{ddv}}$, slope of the $\mathrm{dP} / \mathrm{dt}_{\max }-$ end diastolic volume relation; $\mathrm{E}_{\mathrm{ed}}$, slope of the end diastolic pressure-volume relation; $E_{e s}$, slope of the end systolic pressure-volume relation; $M_{w}$, slope of the stroke work-end diastolic volume relation; $P_{\text {ed }}$, left ventricular end diastolic pressure; $\mathrm{P}_{\max }$, maximum value of left ventricular pressure; $\tau$, time constant of isovolumic relaxation.

DATA ANALYSIS

Each pig acted as its own control. Data for all three doses were analysed by a repeated measures analysis of variance (general linear models procedure, SAS), with multiple comparisons testing using Dunnett's test. Data are reported as mean (SD), and the null hypothesis was rejected if $\mathrm{p}<0.05$.

\section{Results}

Thirty minutes of crystalloid cardioplegic arrest with one hour of cardiopulmonary bypass was sufficient to produce considerable cardiorespiratory instability in neonatal Danish Landrace pigs, necessitating constant surveillance and frequent adjustment of support, analogous to and in some instances greater than the attention required for human neonates. Most pigs experienced episodic supraventricular tachycardia four to eight hours post-bypass. Postoperatively they required $10-15 \mathrm{ml} / \mathrm{kg}$ of blood, $10-30 \mathrm{ml} / \mathrm{kg}$ of polygeline, dobutamine infusions of up to $10 \mu \mathrm{g} / \mathrm{kg} /$ min, and occasional boluses of calcium.

The first four pigs received only the lowest 1-NMMA dose, two showed clear improvement, but two showed minimal change, prompting an expansion of the dose range for subsequent pigs. The three doses covering a 10 -fold dose range should be interpreted as cumulative doses. All three doses were relatively low, with only mild vascular effectsalthough there was a transient increase in systemic and pulmonary artery pressure during the 1-NMMA infusions, by 15 minutes after the infusion, when our measurements were made, there was no significant increase in peak developed left ventricular pressure (table 1). At the time of left ventricular function measurements there was no significant change in heart rate (beats/min) with l-NMMA: control, 196 (18); $5.5 \mathrm{mg}$ 1-NMMA, 185 (12); $37.5 \mathrm{mg}$ 1-NMMA, 193 (16); 75 mg l-NMMA, 186 (17). Linear regressions to determine $\mathrm{E}_{\mathrm{es}}, \mathrm{M}_{\mathrm{w}}$, $\left[\mathrm{dP} / \mathrm{dt}_{\max }\right]_{\text {edv }}$, and $\mathrm{E}_{\text {ed }}$ had mean $r$ values of 0.95 , $0.99,0.95$, and 0.96, respectively. For the group as a whole, $\mathrm{E}_{\mathrm{es}}$ increased with all three doses ( $p=0.009$, fig 1) compared with control, but the increase in $\left[\mathrm{dP} / \mathrm{dt}_{\max }\right]_{\mathrm{edv}}(\mathrm{p}=0.02)$ and the decrease in $P_{\text {ed }}(p=0.03)$ occurred with the two highest doses only. $M_{w}$ and indices of diastolic function other than $\mathrm{P}_{\mathrm{ed}}$ did not change significantly.

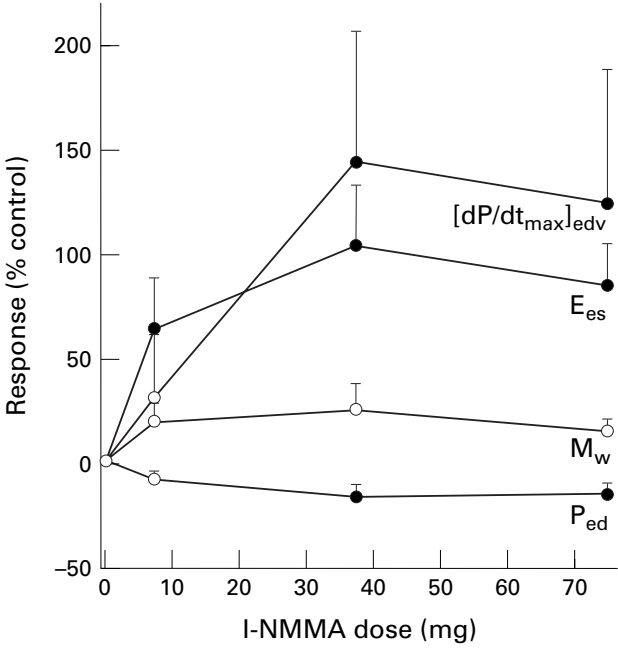

Figure 1 Dose-response of selected indices of left ventricular function to $l-N^{G}$-monomethylarginine (l-NMMA); points are means, error bars = SEM; filled circles are significantly different from control at $p<0.05$. $\left[d P / d t_{\text {max }}\right]_{\text {edv }}$, slope of the $d P / d t_{\max }$-end diastolic volume relation; $E_{e}$, slope of the end systolic pressure-volume relation; $M_{w}$, slope of the stroke work-end diastolic volume relation; $P_{e d}$, left ventricular end diastolic pressure.

\section{Discussion}

The pattern of a delayed contractile deterioration following neonatal open heart surgery is independent of the type of lesion or the quality of the repair, although these factors may affect its severity. ${ }^{1}$ This seems a generalised response to open heart surgery with ischaemic arrest and cardiopulmonary bypass, as a similar temporal profile has been described in adults. ${ }^{13}{ }^{14}$ In this study, non-selective inhibition of nitric oxide synthases by low dose l-NMMA (1.5-15 mg/kg intravenously) 12 hours post-bypass improved left ventricular function over a 10 -fold dose range, as assessed by load independent indices.

LEFT VENTRICULAR RESPONSE TO INHIBITION OF NO SYNTHESIS

Load independent indices of left ventricular function allow separation of the cardiac from the vascular actions of 1-NMMA. ${ }^{9}$ Each of the load independent indices of ventricular function derived from pressure-volume loops measures different aspects of the cardiac cycle and relates the change in a variable to preload, by obtaining the slope of the relation of that variable and end diastolic volume: $\mathrm{E}_{\mathrm{es}}$ deals with end systolic elastance; $\left[\mathrm{dP} / \mathrm{dt}_{\max }\right]_{\mathrm{edv}}$ uses $\mathrm{dP} / \mathrm{dt}_{\max }$ a measure of isovolumic contraction; 
$\mathrm{M}_{\mathrm{w}}$ assesses stroke work and so combines systolic and diastolic information (it is not a pure systolic index); and $\mathrm{E}_{\text {ed }}$ deals with end diastolic elastance.

In this study $\mathrm{E}_{\mathrm{es}}$ and $\left[\mathrm{dP} / \mathrm{dt}_{\max }\right]_{\mathrm{edv}}$ increased and $\mathrm{P}_{\mathrm{ed}}$ decreased significantly. As $\mathrm{E}_{\mathrm{es}}$ and $\left[\mathrm{dP} / \mathrm{dt}_{\max }\right]_{\mathrm{edv}}$ are both load independent indices of systolic function, this implies an unequivocal improvement in left ventricular systolic function. The two pigs which failed to improve with 1-NMMA only received the lowest dose and may have been showing a dose related phenomenon. We believe the smaller change in $M_{w}$ reflects the known decreased sensitivity of this index in comparison with $\mathrm{E}_{\mathrm{es}}$ in detecting changes in contractility. ${ }^{15}$ Improvement in systolic function was presumably the basis for the decrease in $\mathrm{P}_{\text {ed }}$. The absence of major changes in other diastolic indices is at least partly related to our study conditions, in which all measurements were made with an open chest and a widely open pericardium, thus reducing the magnitude of change but allowing a better evaluation of true myocardial diastolic performance. It is reassuring that both the systolic load independent indices $\left(\mathrm{E}_{\mathrm{es}},[\mathrm{dP} /\right.$ $\left.\mathrm{dt}_{\text {max }}\right]_{\text {edv }}$ ) increased significantly at more than one 1-NMMA dose and $\mathrm{P}_{\mathrm{ed}}$ decreased, changes consistent with an improvement in left ventricular function.

POSSIBLE MECHANISM OF ACTION

Pertinent to our model, in which all piglets required dobutamine, is the NO mediated attenuation of $\beta$ adrenergic responses, ${ }^{5616}$ which may also partially explain the relative resistance to inotropes in the postoperative period. It seems unlikely that a Gregg effect (increased contractility with increased coronary perfusion) was involved as there was no sustained increase in aortic pressure and 1-NMMA is a coronary vasoconstrictor.

The response to nitric oxide synthase inhibition is dependent on time and phase of inflammation, as shown in an intestinal vascular inflammation model. ${ }^{17}$ Rats given a nitric oxide synthase inhibitor concurrent with endotoxin developed increased vascular permeability compared with endotoxin alone, whereas nitric oxide synthase inhibition three hours after endotoxin (corresponding to the appearance of inducible nitric oxide synthase activity (iNOS, calcium independent)) decreased vascular permeability. This suggests that in this rat intestine model, the low levels of NO produced by constitutive nitric oxide synthase (cNOS, calcium dependent) had a protective effect, whereas high concentrations produced by iNOS were deleterious. Such a phase of inflammation dependent actions may also exist for other mediators.

During the early reperfusion period in models of cardiopulmonary bypass with ischaemic arrest, most reports suggest that augmentation of NO, whether by NO donors or 1-arginine, is beneficial to ventricular function. ${ }^{518} 19$ A notable exception was a study of reoxygenation during bypass in piglets rendered acutely and severely hypoxic, in which nitric oxide synthase inhibition improved left ventricular function. ${ }^{20}$
This study, however, primarily examined hypoxia-reoxygenation rather than ischaemiareperfusion injury. In an isolated rat heart ischaemia-reperfusion model, nitric oxide synthase inhibition decreased baseline $\mathrm{dP} / \mathrm{dt}_{\max }$ and coronary flow but improved $\mathrm{dP} / \mathrm{dt}_{\max }$ compared with controls after 20 minutes of reperfusion..$^{21}$ In the early reperfusion period NO may be beneficial as it inhibits leucocyte adhesion and platelet aggregation and is a coronary vasodilator. In addition $\mathrm{NO}$ production falls during reperfusion, and augmentation of NO production by l-arginine may be beneficial as it competitively decreases cNOS catalysed superoxide production. ${ }^{22}$ This concept of diminished NO production during reperfusion is supported by a study in children undergoing open heart surgery which showed a decrease in nitrite and nitrate during and immediately following cardiopulmonary bypass. ${ }^{23}$

In our preparation, by 12 hours post-bypass the animals should have been in a later phase of the inflammatory response to cardiopulmonary bypass and ischaemic arrest, and the balance of actions and milieu for NO were presumably very different from the early reperfusion period. Many of the studies in which nitric oxide synthase inhibition improved myocyte twitch or ventricular function are cytokine stimulated or inflammatory models characterised by high NO production by iNOS. As cardiopulmonary bypass is associated with cytokine release, ${ }^{3}$ and a late rise in nitrite/nitrate has been demonstrated following open heart surgery in children, ${ }^{23}$ it is possible that the combined NO production from cNOS and iNOS results in a high NO state. Clearly the pharmacological response to a non-selective nitric oxide synthase inhibitor cannot be used to determine the relative importance of either isoform in this study.

\section{LIMITATIONS OF THE STUDY}

Although a pharmacological response has been demonstrated (improvement in late phase left ventricular dysfunction by low dose 1-NMMA), its mechanism remains to be ascertained. For nitric oxide synthase inhibition in intact animals, recommended intravenous l-NMMA bolus doses are $20-30 \mathrm{mg} / \mathrm{kg}^{24}$ whereas our lowest dose was $1.5 \mathrm{mg} / \mathrm{kg}$ and the total cumulative dose was $24 \mathrm{mg} / \mathrm{kg}$ over approximately 75 minutes. Hence we believe that the 1-NMMA dose range and the dose dependent nature of the responses in this study imply that these are specific actions resulting from nitric oxide synthase inhibition.

Given that in unperturbed hearts ${ }^{525}$ and at physiological concentrations, ${ }^{27} \mathrm{NO}$ inhibition has little effect on cardiac function, it seems likely that in our model — as in other pathophysiological models - there is increased intracardiac or systemic NO production. However, we did not elucidate whether there was an increase in NO production, a change in NOS activity, or isoform expression. Supplementary evidence that 1-NMMA was acting on hearts altered by cardiopulmonary bypass and ischaemia could have been obtained from a control group that did not undergo bypass and ischaemic arrest, 
and in which the 1-NMMA response was assessed after 12 hours. However, given the haemodynamic instability of these pigs we have little doubt that bypass and ischaemia had affected their hearts. Although the highest NO production rates are associated with iNOS, increased cNOS activity may be sufficient to generate high NO concentrations. A nonselective nitric oxide synthase inhibitor was used, as all of the commercially available iNOS inhibitors have only limited dose dependent selectivity; this could have had a confounding effect owing to shifts in the extent of inhibition of different isoforms over the 10-fold dose range used in our study. In addition, the effect of early nitric oxide synthase inhibition (for example, in the first two hours post-reperfusion) on left ventricular function was not examined in this preparation, as this has been extensively documented and produced consistent results in a wide range of species including cats, dogs, lambs, and pigs. ${ }^{18} 192829$

CONCLUSIONS

In neonatal pigs late after cardiopulmonary bypass with ischaemic arrest (12 hours), nitric oxide synthesis inhibition over a 10 -fold dose range of 1-NMMA improved left ventricular function, as measured by load independent indices. This contrasts with the majority of previously published reports of the early reperfusion period in which NO augmentation improves left ventricular function. This indicates important differences in the pathophysiology of the early and late postoperative period, and should prompt further studies of the latter, which is the time of maximum ventricular dysfunction and clinical importance.

This study was funded by the Danish Heart Foundation, the Royal Brompton Hospital Clinical Research Committee, and the Scott Rhodes Research Fund.

1 Burrows FA, Williams WG, Teoh KH, et al. Myocardial performance after repair of congenital cardiac defects in infants and children. $\mathcal{f}$ Thorac Cardiovasc Surg 1988;96:548-56.

2 Wernovsky G, Wypij D, Jonas RA, et al. Postoperative course and haemodynamic profile after the arterial switch and haemodynamic profile after the arterial switch operation in neonates and infants. A comparison of low-flow cardiopulmonary by
Circulation 1995;92:2226-35.

3 Menasche P. The inflammatory response to cardiopulmonary bypass and its impact on post-operative myocardial function. Curr Opin Cardiol 1995;10:597-604.

4 Myocardial preservation in the immature heart. In: Castaneda AR, Jonas RA, Mayer JE, et al, eds. Cardiac surgery of the neonate and infant. Philadelphia: WB Saunders, 1997 $41-53$.

5 Balligand JL, Cannon PJ. Nitric oxide synthases and cardiac muscle, autocrine and paracrine influences. Arterioscle Thromb Vasc Biol 1997;17:1846-58.

6 Lewis NP, Tsao PS, Rickenbacher PR, et al. Induction of nitric oxide synthase in the human cardiac allograft is associated with contractile dysfunction of the left ventricle. Circulation 1996;93:720-9.

7 De Belder AJ, Radomski MW, Why HJ, et al. Myocardial calcium-independent nitric oxide synthase activity is present in dilated cardiomyopathy, myocarditis and postpartum cardiomyopathy but not in ischaemic or valvar heart disease. Br Heart $\mathcal{F}$ 1995;74:426-30.

8 Herbertson MJ, Werner HA, Walley KR. Nitric oxide synthase inhibition partially prevents decreased LV contractility during endotoxaemia. Am f Physiol 1996;270: H1979-84.

9 Kass DA. Myocardial mechanics. In: Poole-Wilson PA, Colucci WS, Massie BM, et al, eds. Heart failure. New York: Churchill Livingstone, 1997:87-108.

10 Baan J, van der Velde ET, de Bruin HG, et al. Continuous measurement of left ventricular volume in animals and humans by conductance catheter. Circulation 1984;70:81223.

11 White PA, Chaturvedi RR, Shore D, et al. Left ventricular parallel conductance during cardiac cycle in children with congenital heart disease. Am f Physiol 1997;273:H295302

12 Chaturvedi RR, Lincoln C, Gothard JWW, et al. Left ventricular dysfunction after open repair of simple congenital heart defects in infants and children: quantitation using a conductance catheter immediately after bypass. F Thorac Cardiovasc Surg 1998;115:77-83.

13 Mangano DT. Biventricular function after myocardial revascularization in humans, deterioration and recovery patterns during the first 24 hours. Anesthesiology 1985;62: 571-7.

14 Breisblatt WM, Stein K, Wolfe CJ, et al. Acute myocardial ysfunction and recovery: a common occurrence after coronary bypass surgery. F Am Coll Cardiol 1990;15:1261-9.

15 Little WC, Cheng CP, Mumma M, et al. Comparison of measures of left ventricular contractile performance derived from pressure-volume loops in conscious dogs. Circulation 1989;80:1378-87.

16 Hare JM, Loh E, Creager MA, et al. Nitric oxide inhibits the positive inotropic response to $\beta$-adrenergic stimulation in humans with left ventricular dysfunction. Circulation 1995; 92:2198-203.

17 Laszlo F, Whittle BJR, Moncada S. Time-dependent enhancement or inhibition of endotoxin-induced vascular injury in rat intestine by nitric oxide synthase inhibitors. $\mathrm{Br}$ I Pharmacol 1994;111:1309-15.

18 Hiramatsu T, Forbess JM, Miura T, et al. Effects of 1-arginine and 1-nitro-arginine methyl ester on recovery of neonatal lamb hearts after cold ischaemia. $\mathcal{F}$ Thorac Cardiovasc Surg 1995;109:81-7.

19 Nakanishi K, Zhao ZQ, Vinten-Johansen J, et al. Blood cardioplegia enhanced with nitric oxide donor SPM-5185 counteracts postischaemic endothelial and ventricular dysfunction. F Thorac Cardiovasc Surg 1995;109:1146-54.

20 Morita K, Ihnken K, Buckberg GD, et al. Role of controlled cardiac reoxygenation in reducing nitric oxide production and cardiac oxidant damage in cyanotic infantile hearts. $\mathcal{F}$ Clin Invest 1994;93:2658-66.

21 Naseem SA, Kontos MC, Rao PS, et al. Sustained inhibition of nitric oxide by $\mathrm{N}^{\mathrm{G}}$-nitro-L-arginine improves myocardial function following ischemia/reperfusion in isolated perfused rat heart. F Mol Cell Cardiol 1995;27:419-26.

22 Huk I, Nanobashvili J, Neumayer C, et al. L-arginine treatment alters the kinetics of nitric oxide and superoxide release and reduces ischaemia/reperfusion injury in skeletal muscle. Circulation 1997;96:667-75.

23 Seghaye MC, Duchateau J, Bruniaux J, et al. Endogenous nitric oxide production and atrial natriuretic peptide biological activity in infants undergoing cardiac operations. Crit Care Med 1997;25:1063-70.

24 Griffith OW, Gross SS. Inhibitors of nitric oxide synthases. In: Feelisch M, Stamler JS, eds. Methods in nitric oxide research. New York: John Wiley, 1996:187-208.

25 Saeki A, Recchia FA, Senzaki H, et al. Minimal role of nitric oxide in basal coronary flow regulation and cardiac energetics of blood-perfused isolated canine heart. F Physiol energetics of blood-perfused

26 Crystal GJ, Gurevicius J. Nitric oxide does not modulate myocardial contractility acutely in in situ canine hearts. $\mathrm{Am}$ f Physiol 1996;270:H1568-76.

27 Weyrich AS, Ma X-L, Buerke M, et al. Physiological concentrations of nitric oxide do not elicit an acute negative inotropic effect in unstimulated cardiac muscle. Circ Res 1994;75:692-700.

28 Weyrich AS, Ma X-L, Lefer A. The role of 1-arginine in ameliorating reperfusion injury after myocardial ischaemia in the cat. Circulation 1992;86:279-88.

29 Pabla R, Buda AJ, Flynn DM, et al. Intracoronary nitric oxide improves postischaemic coronary blood flow and myocardial contractile function. Am $\mathcal{f}$ Physiol 1995;269: H1113-21. 